\title{
Conductivity Structure in and around Hokkaido, Japan as Revealed by the Period Dependence of the CA Transfer Functions
}

\author{
Yasunori NiSHIDA \\ Department of Geophysics, Hokkaido University, \\ Sapporo, Japan
}

(Received April 26, 1982)

\begin{abstract}
The anomalies of geomagnetic variations in Hokkaido at a period of $5 \mathrm{~min}$ are explained by the effect of the induction and the conduction currents within the surface layer such as the conducting sea and the sedimentary layer. However, the behaviour of the anomalies at longer periods than $5 \mathrm{~min}$ is different in each region. From the model calculations to explain the period dependence of the CA transfer functions for each region, the following conclusions are drawn. The highly conducting layer $(0.1 \mathrm{~S} / \mathrm{m})$ exists at a likely depth range from 30 to $70 \mathrm{~km}$ beneath the inner part of the Volcanic Front of the northeastern Japanese arc. On the contrary, the shallower part of the upper mantle beneath the outer part of the Volcanic Front seems to be poorly conducting $\left(10^{-4} \mathrm{~S} / \mathrm{m}\right.$ or so) though a quite thin and highly conducting layer may be present at a depth of about $130 \mathrm{~km}$. These results are consistent with other independent geophysical data such as heat flow and attenuation of seismic waves in and around Hokkaido.
\end{abstract}

\section{Introduction}

Hokkaido is strategically situated at the junction of two island arcs, the Kurile arc and the northeastern Japanese arc, formed by recent geologic activity. It has been considered from a tectonic point of view that the southwestern part of Hokkaido belongs to the northeastern Japanese arc (SUGIMURA and UYEDA, 1973). For the upper mantle below these two arcs, a number of studies have shown that a lateral variation of various physical properties exists. For example, it has been established that $P_{n}$ velocity beneath Hokkaido and the northeastern part of Honshu is about $7 \%$ lower than that beneath the region between the Pacific coast and the Japan-Kurile trench (AsANo et al., 1978; OKADA et al., 1978; SUZUKI, 1978). A boundary at which change in the $P_{n}$ velocity occurs is inferred to be almost coincident with the "Aseismic Front" proposed by YosHII (1975). It has been inferred from the terrestrial heat flow data that the temperature in the crust and the upper mantle is much higher in the inner part of the "Volcanic Front" (SUGIMURA, 1960; SUGIMURA et al., 1963) than that in the outer part (WATANABE, 1968; UYEDA, 1972; EhARA, 1971, 1979). The tectonic map is shown in Fig. 1.

We must say that great interest is focussed on the electric conductivity structure in the upper mantle of the island arc. In order to search this problem, the observations of the geomagnetic variations in short periods have been carried out at many temporary stations in Hokkaido and the northeastern part of Honshu. Anomalous enhancement in the vertical 
and the horizontal components of the geomagnetic variations was found at many places from these observations (KATO et al., 1971; MoRI, 1975; NiSHIDA, 1976, 1977a, b, 1981; Yamashita and Yokoyama, 1975, 1977; UyedA and Oshima, 1979). The Parkinson vectors at a period of $5 \mathrm{~min}$ tend to point to the direction of the adjacent sea and the sedimentary basin. These short period anomalies are successfully interpreted as the effect of the induction and the conduction currents within the conducting sea and the sediments, by comparing the observed geomagnetic field with calculated one on the basis of a nonuniform thin sheet model (NISHIDA, 1976). However, the deeper conductivity structure is not yet clear.

The period dependence of the observed geomagnetic variation anomalies is different in each region. At some stations, the amplitude of the anomalous $Z$-field originated from the surface currents falls off rapidly at longer periods than $5 \mathrm{~min}$, while no remarkable period dependence is observed at other stations. Such behaviour of the period dependence must provide a clue to elucidate the deeper conductivity structure. In this paper, the deeper conductivity structure in and around Hokkaido is discussed on the basis of the analysis of the period dependence of the geomagnetic variation anomalies.

\section{The Period Dependence of the CA Transfer Functions}

The magnetic points are shown in Fig. 2 with the abbreviated station names which will be referred in the present paper. The CA transfer functions have already been obtained at these stations (MORI, 1975; NisHIDA, 1976, 1977a, b; YAMASHITA and YoKoYAMA, 1975, 1977; UYEDA and OSHIMA, 1979). Only the real part of the transfer function is used in this paper because the imaginary part is significantly smaller than the real one at almost all stations in Hokkaido (NiSHIDA, 1976). From the period dependence of the transfer functions in Hokkaido and the northernmost part of Honshu, remarkable features can be easily recognized in the following three regions.

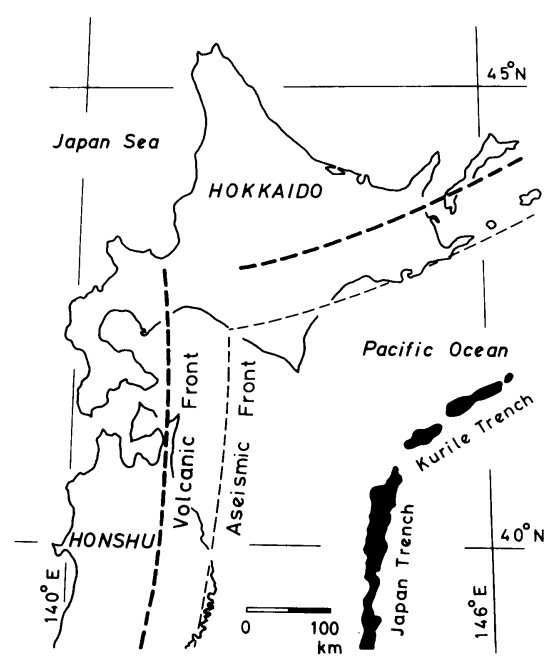

Fig. 1. Tectonic map of Hokkaido and the northeastern part of Honshu. 


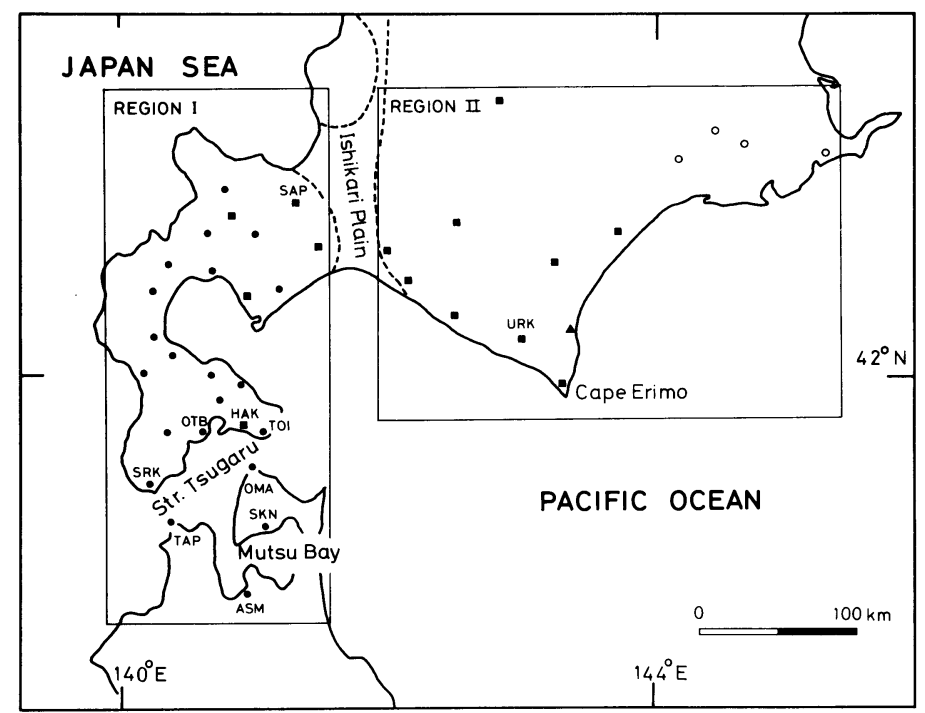

Fig. 2. Location of the magnetic points. Solid squares, after NiSHIDA (1976, 1977a); solid circles, after YAMASHITA and YoKoyama $(1975,1977)$; hollow circles, after MoRI (1975); solid triangle, after UYEDA and OsHIMA (1979).

a) Cape Erimo region: The anomalies of the geomagnetic variations in this region are explained by the peninsula effect of Cape Erimo as clearly illustrated by the Parkinson vectors in $a$-region of Fig. 3. The dashed and the solid vectors denote the Parkinson vectors at periods of 5 and 60 min respectively. As shown in the example of Fig. 4a, the large transfer functions $A$ and $B$ at URK have no remarkable period dependence for a period range from a few minutes to about 20 min though the values decrease gradually at longer periods. Therefore, the peninsula effect still remains at longer periods.

b) The Ishikari Plain: The Ishikari Plain, which has almost north-south strike, is covered with the conducting sediments over a few $\mathrm{km}$. At a period of $5 \mathrm{~min}$, a clear reversal of direction of the Parkinson vectors can be seen at the stations across the plain ( $b$-region in Fig. 3). These anomalies are already explained by the channel effect that the induced currents within the Japan Sea and the Pacific Ocean flow into the narrow Ishikari Plain (NisHIDA, 1977a). However, the transfer function $B$ at SAP, for example, changes the sign when the period becomes longer than about $10 \mathrm{~min}$ (Fig. $4 \mathrm{~b}$ ). Then, the vectors at the stations in the west of the plain turn toward north or west-northwest at a period of $60 \mathrm{~min}$. This suggests an upheaval of the underground conductor at the west of the plain.

c) The Tsugaru Straits region: The period dependence of the transfer function is remarkable in the southwestern part of Hokkaido. Especially, a peculiar feature is found at the coastal regions of the Tsugaru Straits and the Bay of Mutsu. Since the Parkinson vectors at a period of $5 \mathrm{~min}$ in $\mathrm{c}$-region (Fig. 3) are large and point to the strait, it is evident that the anomalies of the geomagnetic variations are caused by the east-west current concentration. However, the anomalies at longer periods are very different from those as expected in case of the simple channel effect. We can classify the pattern of the period dependence of the 


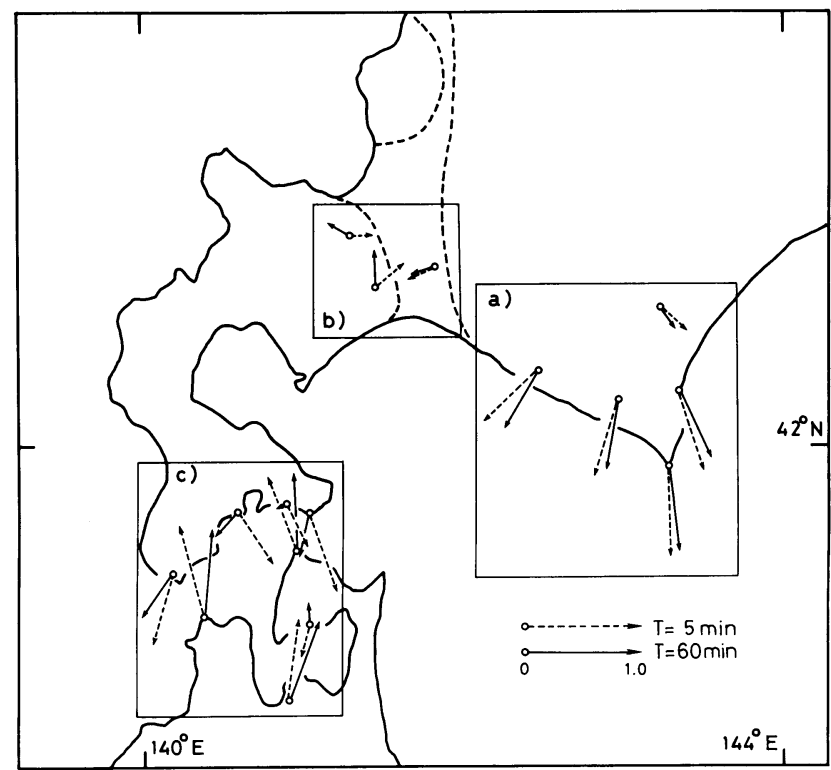

Fig. 3. The Parkinson vectors at periods 5 and $60 \mathrm{~min}$.
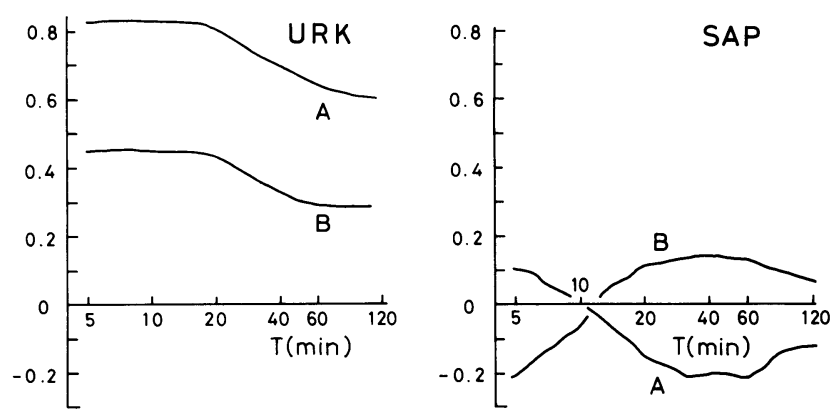

Fig. 4. Examples of the period dependence of the transfer functions $A$ and $B$.

transfer function $A$ under two groups: the northern coast type (the $\mathrm{N}$-type) and the southern coast type (the S-type). The two patterns appear alternately at the northern and the southern coasts of the Tsugaru Straits and the Bay of Mutsu, as clearly illustrated in Fig. 5a. At the stations on the northern coast of the Tsugaru Straits (HAK, OTB, TOI, and SRK) as well as a station on the Bay of Mutsu (SRK), the quite large value of $A$ at short period falls off rapidly to a certain level as the period becomes longer. We call it $\mathrm{N}$-type anomaly. Especially at SKN, the transfer function $A$ changes its sign to negative, so that the Parkinson vector at a period of 60 min points in a northward direction, opposite to the 

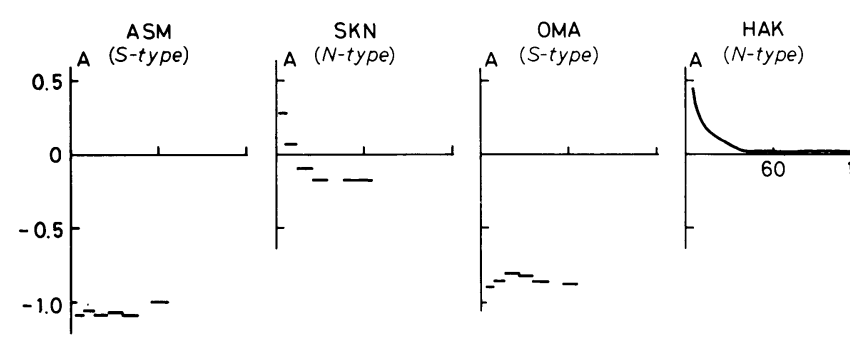

a)
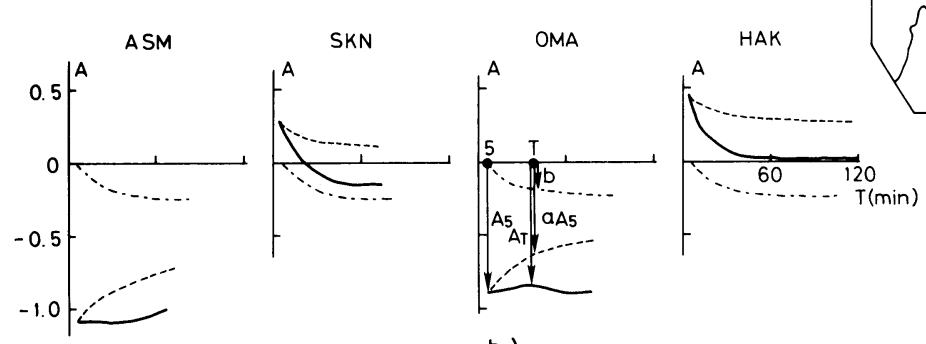

$T(\min )$

b )

Fig. 5. a) Period dependence of the transfer function $A$. The values at ASM, SKN, and OMA are determined by the classical method. The amplitude of the geomagnetic variations is defined as the maximum deviation from a straight line connecting the beginning of an event with its end on each magnetogram. The period is taken as the time from the beginning of an event to its end. b) Schematic representation of the reducing factor (dashed curves) and the regional trend (dotdashed curves).

adjacent coast line. On the other hand, the transfer function $A$ with negative sign shows no remarkable period dependence for a period range from 5 to $120 \mathrm{~min}$ at the southern coast stations (OMA, ASM, and TAP). This type of anomaly is classified as the S-type.

The possible cause of the complicated behaviour of the CA transfer functions in the $c$ region is discussed here. This will provide us with the key to infer the subterranean conductivity structure beneath Hokkaido. The transfer functions at a period of $5 \mathrm{~min}$ in Hokkaido are successfully interpreted by electric currents induced in the surface conductor (NishidA, 1976, 1977a). The calculated intensity of regional induced currents in a single thin sheet is nearly constant for a period range from 5 to $120 \mathrm{~min}$. Thus, other factors must be taken into account, to explain the period-dependent characteristics in the $c$-region.

When electromagnetic coupling effect between the surface sheet and the subterranean conducting layer is taken into consideration, such a coupling weakens the current intensity in the surface sheet, so that it attenuates the anomalous $Z$-variations. The coupling effect, and consequently the attenuation of the transfer functions, must be dominant at relatively longer periods, when the skin depth of the surface sheet is taken into account. Therefore, the effect is favorable to explain the $\mathrm{N}$-type anomaly. If so, however, the absolute value of $A$ at the S-type stations should be also smaller in magnitude at longer periods, contrary to the observed flat response. Even at the $\mathrm{N}$-type stations, the coupling effect can hardly change the sign of the transfer function, as seen in case of SKN (Fig. 5a). 
YAMASHITA and YoKoYAma (1977) found in the $c$-region that the local anomalies due to the surface currents are biased by a regional trend which adds a certain amount of negative value on $A$ at periods longer than $5 \mathrm{~min}$. The bias on the transfer functions is presumed by them to be almost uniform over the $c$-region. The $\mathrm{N}$-type anomaly can be interpreted by this effect. However, we again fail to explain the observed flat response of the S-type anomaly because the absolute value of $A$ at the S-type stations should be large at longer periods than $5 \mathrm{~min}$ in consequence of the biased field.

To remedy the deficiency of the both interpretations, it can be considered that the transfer function at periods longer than 5 min consists of two parts, the reduced transfer function due to the coupling effect and the regional trend: The local transfer function due to the surface currents is reduced with increasing period, as schematically shown in Fig. 5b. The regional trend also decreases from zero value at a period of $5 \mathrm{~min}$ to a certain negative level up to a period of $120 \mathrm{~min}$. Adding both parts, we can reproduce the typical $\mathrm{N}$ - and Stype anomalies. The situation seems to be similar to the case in the central part of Japan. The anomalies of the geomagnetic variations at the islands such as O-shima and Miyakejima are thought to be composed of the island effect and the large-scale "Central Japan Anomaly" (SASAI, 1967; HonkURA, 1971).

\section{Separation of the Reducing Factor and the Regional Trend}

In the present case, the transfer function $A$ at a certain period of $T$ can be represented as follows :

$$
A_{T}=a A_{5}+b
$$

where the coefficients $a$ and $b$ represent the reducing factor and the regional trend, respectively. These coefficients are the function of period. $A_{5}$ denotes the transfer function $A$ at a period of $5 \mathrm{~min}$. This relation is clearly shown in an example of OMA in Fig. $5 \mathrm{~b}$. The transfer function $B$ is also expressed in the same manner as $B_{T}=c B_{5}+d$. The reducing factor of the local transfer function is thought to be common at all stations in $a$-region, because this factor is determined solely by the regional current intensity.

The objective stations are divided into two groups situated at the southwestern part of Hokkaido and the northernmost part of Honshu (Region I in Fig. 2), and the other part (Region II in Fig. 2). The regions I and II are situated at the inner and the outer parts of the Volcanic Front, respectively. The eastern border of the region I almost coincides with the Volcanic Front of the northeastern Japanese arc and with the western border of the Ishikari Plain (Figs. 1 and 2). The reason why the Ishikari Plain is excluded from the objective region will be given in the latter section.

The transfer function $A_{T}\left(B_{T}\right)$ at the stations in each region is plotted against $A_{5}\left(B_{5}\right)$, as shown in Fig. 6. The solid and the hollow circles represent the data obtained from the regions I and II, respectively. From the linear approximation using the least square method, we can get the reducing factors $(a$ and $c$ ) and the regional trends ( $b$ and $d$ ). Only few dispersed data are omitted in the figure. The coefficients, particularly $a$ and $b$, are surprisingly well determined at each region: The tendency of the period dependence is common at the stations within each region.

Figure 7 shows the period dependence of the reducing factors and the regional trends. 

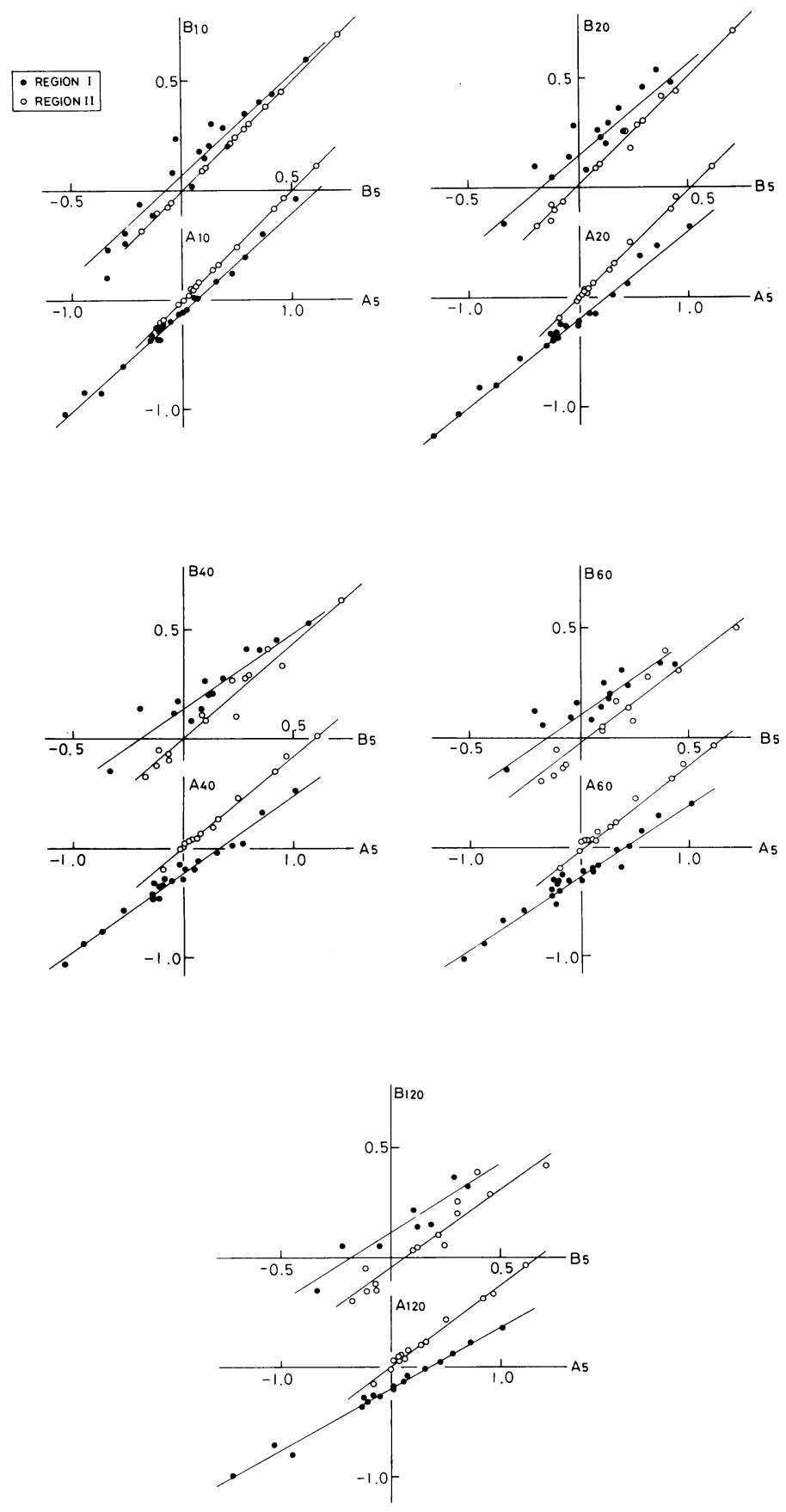

Fig. 6. The relation between the transfer functions $A_{5}$ and $A_{T}\left(B_{5}\right.$ and $\left.B_{T}\right)$ for the regions I and II. Subscripts 5 and $T$ denote the period in unit of minute. 


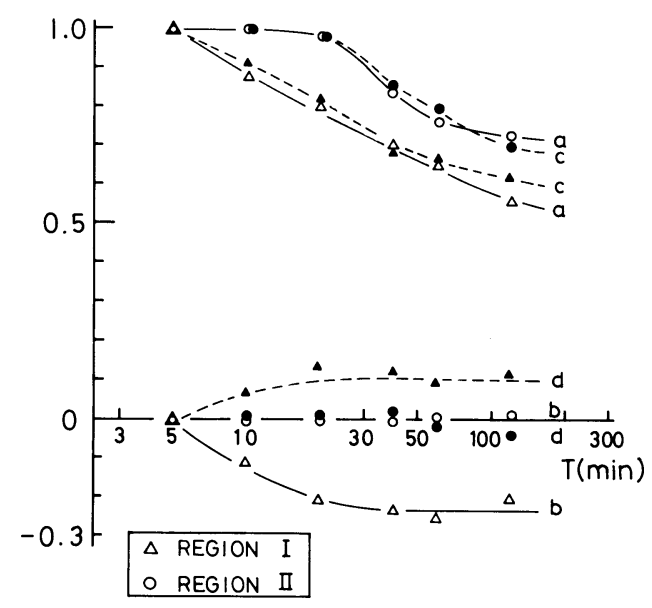

Fig. 7. Period dependence of the reducing factors $(a$ and $c)$ and the regional trends $(b$ and $d)$.

It is seen from this figure that the two regions are significantly different from each other in period dependence though the regions quite adjoin. At the region $I$, the regional trend clearly appears. Especially, $b$ amounts to -0.22 at longer periods. On the other hand, the values are negligibly small at the region II. Existence of some amount of $Z$-component in the inducing field is a possible explanation of the origin of the regional trend. If so, however, some appreciable amount of the regional trend should also be obtained at the region II because of the large spatial wave length of the inducing field. Another explanation is that the surface of the conductor beneath the region $I$ is inclined to be shallower at the northern part of the region. The fact that the terrestrial heat flow is large at the northern part of the region (EHARA, 1979) is consistent with the above-mentioned explanation. However, further discussions about the origin of the regional trend will be left for another occasion.

The reducing factors $a$ and $c$ at the region I fall off monotonously at longer periods than $5 \mathrm{~min}$, while those in region II are almost constant from 5 to about $20 \mathrm{~min}$ in period and fall off for a period range from 20 to $40 \mathrm{~min}$. Since the reducing factors are obtained here as a function of period, we can determine the subterranean conductivity structure which produces specified regional currents through the coupling effect. This is a useful idea originally devised by HoNKURA (1973) in his study of the Miyake-jima anomaly. Considering the distribution of the observation points, the period dependence of the reducing factors in the region I may largely be affected by the conductivity structure beneath the inner part of the Volcanic Front of the northeastern Japanese arc including the adjacent Japan Sea and the Tsugaru Straits. On the other hand, the data obtained from the region II may rather reflect the structure beneath the outer part of the Volcanic Front including the adjacent Pacific Ocean, though the lateral extent of each structure cannot be defined strictly.

\section{Model Calculation}

We consider the earth model, as shown in Fig. 8, where the conductivity within the 


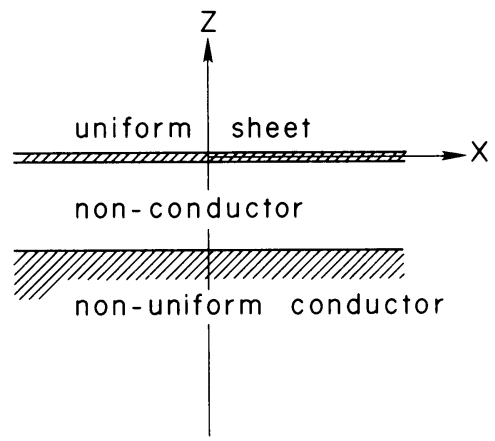

Fig. 8. The earth model.

non-uniform conductor is an arbitrary function of $z$. When the probable inducing field is applied to the earth, the currents induced in the uniform thin sheet can be calculated numerically for various periods. The procedure for calculation is given by HoNKURA (1973) in detail. In case of electromagnetic induction within a non-uniform thin sheet conductor, the induced currents can be separated to the regional and the locally distorted parts (SASAI, 1968). When the effects of the self-induction in the surface layer and of the mutual induction between the distorted currents and the subterranean conducting layer can be ignored, the amplitude of the locally induced field is thought to be proportional to the currents induced in the uniform sheet of the earth model. Although such a treatment is not sufficiently justified in the present case in contrast with the case that the objective region is considered to be small in scale, these assumptions may be acceptable with a certain degree of approximation.

The transfer function is represented as the ratio of the vertical component to the horizontal one. For example, the transfer function $A$ can be expressed as:

$$
A=\frac{\Delta Z}{\Delta H}=\frac{\Delta Z_{\mathrm{ex}}+\Delta Z_{\mathrm{in}}}{\Delta H_{\mathrm{n}}+\Delta H_{\mathrm{a}}}
$$

when the inducing field points to the north-south direction. $\Delta Z_{\text {ex }}$ and $\Delta Z_{\text {in }}$ denote the external and the internal parts of $Z$-field, respectively, while $\Delta H_{\mathrm{n}}$ and $\Delta H_{\mathrm{a}}$ denote the normal and the anomalous parts of $H$-field, respectively. A is well approximated by $\Delta Z_{\text {in }} / \Delta H_{\mathrm{n}}$ under the condition that $\Delta Z_{\mathrm{ex}}$ and $\Delta H_{\mathrm{a}}$ can be neglected. In such a case, it can be said that the transfer functions are approximately proportional to the currents induced in the surface layer of the above-mentioned earth model. Generally speaking, the vertical component of the inducing field is much smaller than the horizontal one in the middle latitude like Japan. The Ishikari Plain, where the anomalous enhancement in the horizontal component was observed (NISHIDA, 1981), is excluded from the objective region of this study. Therefore, the above-mentioned conditions are satisfied in the present study.

We are now in a position to search for conductivity models which lead to agreement between the period dependence of the transfer functions and that of the intensity of the surface currents induced in the uniform thin sheet. In case of the present calculation, we should give the integrated conductivity $\sigma$ of the uniform thin sheet. Hokkaido is 
surrounded by the Japan Sea and the Pacific Ocean of the depth of about 4,500 $\mathrm{m}$ as a mean value. $\sigma$ is $1.8 \times 10^{4} \mathrm{~S}$ in this case because $\sigma$ is taken as $\left(\int_{0}^{D} \sigma_{0} \mathrm{~d} s=\sigma_{0} D\right)$ when $D$ and $\sigma_{0}$ denote the depth of the sea and electric conductivity of the sea water $\left(\sigma_{0}=4 \mathrm{~S} / \mathrm{m}\right)$. But we cannot assume the infinite sheet with such integrated conductivity because the induced currents around Japan tend to be largely deflected from the poorly conducting Asian Continent. RIKITAKE (1967) calculated the induced currents in a spherical sheet, which represents the large-scale non-uniform conductivity distribution of the earth's surface. Comparing his result with the currents induced in the uniform spherical sheet, the currents induced around Japan are equivalent to those induced in the uniform spherical sheet with the integrated conductivity of $6.8 \times 10^{3} \mathrm{~S}$ which corresponds to the sea depth of about $1,700 \mathrm{~m}$. Therefore, the conductivity of $6.8 \times 10^{3} \mathrm{~S}$ is used in this study.

The calculated surface current functions normalized to the current function at a period of $5 \mathrm{~min}$ are compared with the reducing factors $a$ and $c$. Among many trial models, two examples are shown in Fig. 9 for the convenience of comparison. The response of these models does not agree with the period dependence of $a$ and $c$ at longer periods. This is because the conductivity is too high in the deeper part of the models. Figure 10 denotes the conductivity models with a favorable response, as shown in Fig. 11, although the models are by no means unique. The models I and II correspond to the structures beneath the inner part of the Volcanic Front of the northeastern Japanese arc and the outer part of the Volcanic Front respectively. The existence of the highly conducting layer $(0.1 \mathrm{~S} / \mathrm{m})$ at a likely depth range from 30 to $70 \mathrm{~km}$ is characteristic in the model I. The poor conductivity of $10^{-4} \mathrm{~S} / \mathrm{m}$ or so, on the contrary, is estimated at the shallower part of the upper mantle in the model II though the existence of a quite thin and highly conducting layer is present at a depth of about $130 \mathrm{~km}$.

\section{Discussion and Concluding Remarks}

The two models, which may represent the approximate structure in and around Hokkaido, are presented in the previous section. Especially, the discrepancy between the

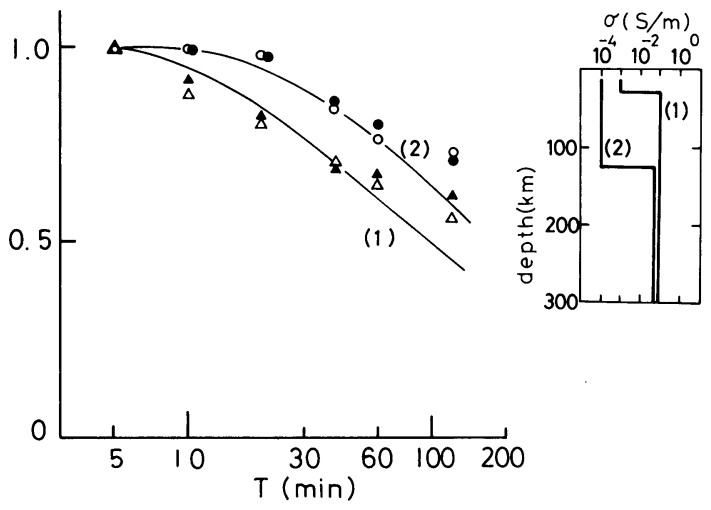

Fig. 9. Theoretical surface current functions normalized to the current function at a period of 5 min. Models used for the calculation are also shown. Circles and triangles denote the reducing factors $a$ and $c$. 


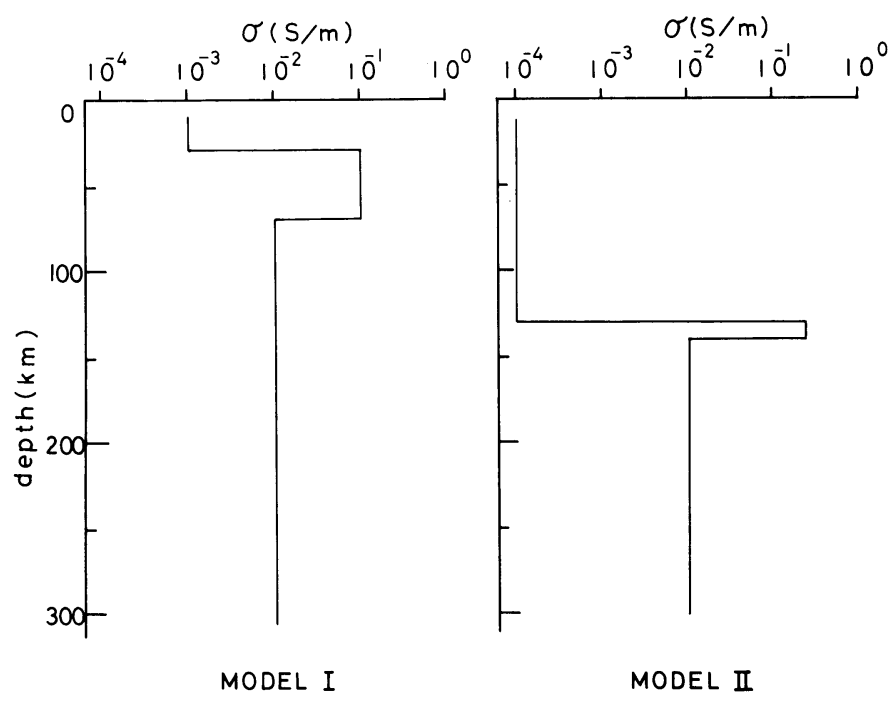

Fig. 10. Models of electric conductivity distribution.

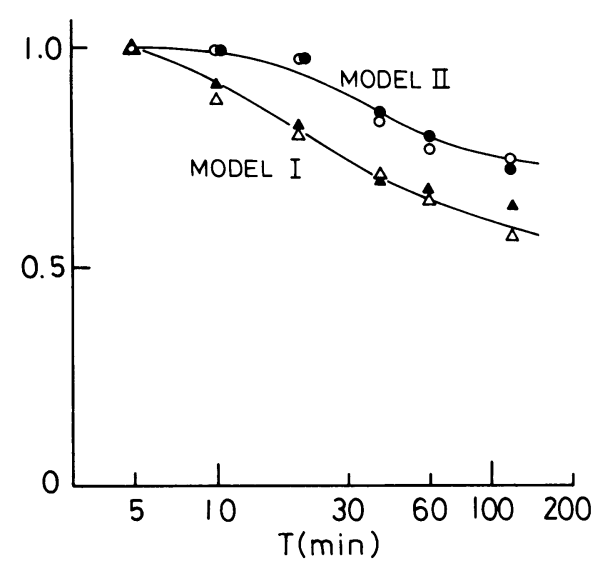

Fig. 11. Theoretical surface current functions for models shown in Fig. 10. Circles and triangles denote the reducing factors $a$ and $c$.

two models is thought to be significant. It is demonstrated that the highly conducting layer in and around the region I upheaves close to the earth's surface in contrast with the case of the region II.

As previously described, the direction of the Parkinson vectors in the west of the Ishikari Plain turns from east to north or west-northwest as the period becomes longer (Fig. 3). Judging from this fact, it may be concluded that the magnetic field originated from the mantle conducting layer, situated at the west of the Ishikari Plain, cancels the $Z$-component 
derived from the surface conducting layer. Therefore, it is quite probable that the eastern end of the highly conducting layer shown in the model I situates at the western border of the plain which is almost coincident with the Volcanic Front of the northeastern Japanese arc.

According to the detailed heat flow measurements by EHARA $(1971,1979)$, the high heat flow values beyond $84 \mathrm{~mW} / \mathrm{m}^{2}$ ( $2 \mathrm{HFU}$ ) are obtained in the region I and the high heat flow region extends to the Sea of Japan. On the other hand, the values decrease stepwisely to $42 \mathrm{~mW} / \mathrm{m}^{2}$ (1 HFU) or so at the Volcanic Front of the northeastern Japanese arc and the low heat flow region extends to the east of this boundary. High attenuation of seismic waves $(Q<100)$ is characteristic in the region I (MoRIYA, 1978). These independent other geophysical data support the above-mentioned concept of the conductivity structure.

The present analysis involves some problems to be solved. 1) The effects of the selfinduction in the surface layer and of the mutual induction between the distorted currents and the subterranean conducting layer have not been taken into consideration. It is obvious that such effects cannot be neglected in the present case because the horizontal scale of the region is large. 2) The model calculation has been made on the basis of the earth model with a vertically one-dimensional structure. Therefore, the actual extent of the obtained structures could not be limited though the eastern border of the model I was estimated from the direction of the Parkinson vectors. The two- or three-dimensional model calculations will give us a more improved conductivity structure. In that case, the suboceanic structures obtained from the electromagnetic observations on the surrounding ocean-floor will provide the relevant boundary conditions.

The writer would like to express his sincere thanks to Prof. I. Yokoyama for his valuable discussions. Mr. H. Yamashita, Usu Volcano Observatory, kindly accepted my proposal to utilize his unpublished data to the present analysis. The writer is also grateful to Mr. Y. Sasai, University of Tokyo, for his helpful discussions. The computation was carried out on HITAC M200H at the Computing Center of Hokkaido University.

\section{REFERENCES}

asano, S., H. Okada, T. Yoshi, K. Yamamoto, T. Hasegawa, K. Ito, S. Suzuki, A. IKami, and K. Hamada, Crust and upper mantle structure beneath northeastern Honshu, Japan as derived from explosion seismic observations, J. Phys. Earth, 27, Suppl., S1-S13, 1979.

Ehara, S., Terrestrial heat flow in Hokkaido, Japan - Preliminary report-, J. Fac. Sci., Hokkaido Univ., Ser. VII, 3, 443-460, 1971.

Ehara, S., Heat flow in the Hokkaido-Okhotsk region and its tectonic implications, J. Phys. Earth, 27, Suppl., S125-S139, 1979.

HONKURA, Y., Geomagnetic variation anomaly on Miyake-jima Island, J. Geomag. Geoelectr., 23, 307-333, 1971.

HoNKURA, Y., Island effect and electrical conductivity structure beneath Miyake-jima Island, J. Geomag. Geoelectr., 25, 167-179, 1973.

Kato, Y., M. Daguchi, M. Seto, and T. ARiga, Northeastern Japan anomaly of the upper mantle, Sci. Rep. Tohoku Univ., Ser V, 21, 19-35, 1971.

MoRI, T., Conductivity anomalies in the eastern part of Hokkaido, Japan. Mem. Kakioka Mag. Obs., 16, 79-93, 1975.

MorIYA, T., Seismic studies of the upper mantle beneath the arc-junction at Hokkaido: Folded structure of intermediate depth seismic zone and attenuation of seismic waves, J. Phys. Earth, 26, Suppl., S467-S475, 1978.

NishidA, Y., Conductivity anomalies in the southern-half of Hokkaido, Japan, J. Geomag. Geoelectr., 28, 375-394, 1976. 
NishidA, Y., Conductivity anomalies in and around the Ishikari Plain, Hokkaido, Geophys. Bull. Hokkaido Univ., 36, 17-28, 1977a (in Japanese with English abstract).

NiSHIDA, Y., Observations of geomagnetic and geoelectric variations along the north-south profile of Hokkaido, Geophys. Bull. Hokkaido Univ., 36, 29-40, 1977b (in Japanese with English abstract).

NishidA, Y., Anomalous behaviour in the horizontal components of geomagnetic variations in Hokkaido, Japan, J. Geomag. Geoelectr., 33, 43-50, 1981.

Okada, H., S. Asano, T. YoshiI, A Ikami, S. Suzuki, T. Hasegawa, K. Yamamoto, K. Ito, and K. Hamada, Regionality of the upper mantle around northeastern Japan as revealed by big explosions at sea, I. SEIHA-1 explosion experiment, J. Phys. Earth, 27, Suppl., S15-S32, 1979.

RikitaKe, T., Electromagnetic induction within non-uniform plane and spherical sheets, Bull. Earthq. Res. Inst., 45, 1229-1294, 1967.

SaSAI, Y., Spatial dependence of short-period geomagnetic fluctuations on Oshima Island (1), Bull. Earthq. Res. Inst., 45, 137-157, 1967.

SASAI, Y., Spatial dependence of short-period geomagnetic fluctuations on Oshima Island (2), Bull. Earthq. Res. Inst., 46, 907-926, 1968.

SugimurA, A., Zonal arrangement of some geophysical and petrological features in Japan and its environs, J. Fac. Sci., Univ. Tokyo, Sec. II, 12, 133-153, 1960.

Sugimura, A., T. Matsuda, K. Chinzei, and K. NAKamura, Quantitative distribution of late Cenozoic volcanic materials in Japan, Bull. Volcanol., 26, 125-140, 1963.

Sugimura, A. and S. UyedA, Island Arcs: Japan and Its Environs, Elsevier, Amsterdam, 1973.

SUZUKI, S., Lateral variation of the upper mantle structure around northern Japan and its application to hypocenter determination, J. Fac. Sci., Hokkaido Univ., Ser. VII, 5, 79-120, 1978.

UyedA, S., Heat flow, The Crust and Upper Mantle of the Japanese Area, Part 1, Chap. V edited by S. Miyamura and S. Uyeda, pp. 97-105, Earthq. Res. Inst., Univ. Tokyo, 1972.

UyedA, Y. and S. Oshima, The CA transfer functions in the geomagnetic repeat stations of Hydrographic Office, Proc. Conductivity Anomaly Symp., Earthq. Res. Inst., Univ. Tokyo, 39-44, 1979 (in Japanese).

Watanabe, T., Temperature profiles at continental margins, Proc. Conductivity Anomaly Symp., Earthq. Res. Inst., Univ. Tokyo, 167-182, 1968 (in Japanese).

YAMASHITA, H. and I. YoKoYama, Geomagnetic variations of short period in the southwestern part of Hokkaido (Part 1), Geophys. Bull. Hokkaido Univ., 34, 15-44, 1975 (in Japanese with English abstract).

Yamashita, H. and I. Yokoyama, Geomagnetic variations of short period in the southwestern part of Hokkaido (Part 2), Geophys. Bull. Hokkaido Univ., 36, 41-58, 1977 (in Japanese with English abstract).

YoshII, T., Proposal of the "Aseismic Front," Zisin, 28, 365-367, 1975 (in Japanese). 